\title{
Meningkatkan Kreativitas Anak Usia Dini Melalui Pembelajaran Gerak dan Lagu
}

\author{
Hapsah Rahayu ${ }^{1 凶}$, Elindra Yetti ${ }^{2}$, Yetti Supriyati ${ }^{3}$ \\ Penddikan Anak Usia Dini, Universitas Negeri Jakarta \\ DOI: $10.31004 /$ obsesi.v5i1.691
}

\begin{abstract}
Abstrak
Tujuan dari penelitian ini adalah untuk mengetahui proses implementasi pembelajaran gerak dan lagu untuk meningkatkan kreativitas anak usia 5-6 tahun. Metode penelitian yang digunakan adalah penelitian tindakan model Kemmis dan Mc. Taggart. Subjek penelitian anak usia 5-6 tahun di TK Islam Tasya Cibinong. Analisis data pada penelitian ini menggunakan deskriptif kualitatif dan kuantitatif. Hasil penelitian menunjukkan pra siklus yang dilakukan mendapat nilai $36,036 \%$, setelah siklus I terjadi peningkatan $45,85 \%$ dan siklus II sebesar $71,058 \%$. Hal ini menunjukkan bahwa kreativitas anak meningkat dengan baik melalui pembelajaran gerak dan lagu. Pembelajaran gerak dan lagu memiliki pengaruh yang sangat penting untuk perkembangan anak, salah satunya kreativitas.
\end{abstract}

Kata Kunci: kreativitas;anak usia dini; gerak dan lagu.

\begin{abstract}
The purpose of this study was to see the implementation process of learning motion and songs to increase the creativity of children aged 5-6 years. The research method used is action research model Kemmis and Mc. Taggart. The research subjects were children aged 5-6 years in Tasya Cibinong Islamic Kindergarten. The data analysis in this study used descriptive qualitative and quantitative. The results showed that the pre-cycle carried out got a value of $36.036 \%$, after the first cycle there was an increase of $45.85 \%$ and the second cycle was $71.058 \%$. This shows that children's creativity improves well through learning movements and songs. Learning motion and songs have a very important influence on children's development, one of which is creativity.
\end{abstract}

Keywords: creativity; early childhood; motion and song.

Copyright (c) 2020 Hapsah Rahayu, Elindra Yetti, Yeti Supriyati

$\triangle$ Corresponding author:

Email Address : email koresponden@gmail.com ( alamat, koresponden )

Received tanggal bulan tahun, Accepted tanggal bulan tahun, Published tanggal bulan tahun

\section{PENDAHULUAN}

Pendidikan anak usia dini adalah pendidikan yang disediakan untuk anak usia dini dengan tujuan untuk membantu anak agar dapat berkembang seluruh aspek dalam dirinya dan mengoptimalkan potensi disetiap aspek perkembangannya, dan anak siap melanjutkan pendidikan ke tingkat selanjutnya (Ayuni \& Setiawati, 2019). Hal ini sependapat dengan Dere (2019) bahwa lembaga pendidikan anak usia dini merupakan sekolah yang membantu mendidik dan menstimulasi perkembangan anak usia dini. Pendidikan anak usia dini 
memberikan pengalaman pembelajaran bagi anak. Adapun tujuan dari pendidikan anak usia dini adalah mengembangkan aspek perkembangan anak, agar anak memiliki kesipan untuk pendidikan selannjutnya.

Salah aspek perlu dikembangkan sejak usia dini adalah kreativitas (Elya et al., 2019). Pengembangan kreativitas anak sangat penting dikembangkan untuk menyiapkan pendidikan anak sekaligus masa depan anak nantinya (Elya et al., 2019). Proses kreativitas berkaitan dengan kognitif anak, dengan kreativitas anak dapat mengungkapkan ide-ide atau gagasan yang ada dipikiran anak dan memiliki dampak yang baik untuk masa depannya (Glăveanu, 2011; Tsai, 2012). Sependapat dengan Suryani \& Haryono (2018) bahwa kreativitas pada anak usia dini berkaitan dengan kognitif anak karena berhubungan dengan proses berpikir dalam mengungkapkan pendapat, memikirkan cara-cara baru, dan problem solving.

Menurut Susanto (2011) adapun komponen dasar aspek kreativitas yaitu: (1) Kelancaran, meliputi: ekspresif, arus gagasan spontan, menggunakan waktu untuk menemukan solusi. (2) Kelenturan, meliputi: cenderung mengadakan percobaan sendiri, tidak menggunakan metode umum dalam menyelesaikan masalah, melakukan oendekatan, sudut pandang dari perspektif yang berbeda, toleransi, kemampuan menyesuaikan diri. (3) Keaslian, meliputi: imajinasi tinggi, tidak terpengaruh dari luar, cenderung mengadakan percobaan. (4) Penguraian, meliputi: penggunaan banyak unsur dan menggunakan ide-ide. Untuk meningkatkan kreativitas anak usia dini dapat melalui pembelajaran yang menyenangkan dan bervariasi seperti pembelajaran gerak dan lagu.

Pembelajaran gerak dan lagu mampu mengembangkan perkembangan anak, seperti: perkembangan kepribadian anak, imajinasi, social, emosi, motoric, kognitif, serta krativitas anak (Kralova \& KolodziejskiZ, 2016). Sementara Gerak dan lagu menurut Sujiono (2010) gerak dan lagu adalah gerakan yang dilakukan anak berdasarkan syair lagu yang biasanya dinyanyikan oleh anak secara bersama-sama. Syair lagu mengarahkan atau menuntun anak pada gerakan yang meniru gerakan dalam lagu tersebut. Samsudin et al., (2019) pembelajaran lagu dan gerak adalah salah satu unsur yang digunakan dalam proses pembelajaran pendidikan anak usia dini. Hasil penelitian bahwa penggunaan elemen music dan gerakan dapat menarik perhatian dan focus pada anak usia dini. Untuk itu, guru pendidikan anak usia dini dapat memvariasikan pendekatan pengajaran dengan pembelajaran music dan gerak. Karena gerak dan lagu bermanfaat dalam menarik perhatian serta minat anak.

Berdasarkan observasi yang dilakukan di TK Islam Tasya Cibinong kemapuan perkembangan anak sudah berkembangan dengan baik, seperti: nilai moral dan agama, social-emosional, kognitif, fisik-motorik dan bahasa. Sedangkan kreativitas anak belum berkembang dengan baik. Hal ini ditinjukkan bahwa 4 orang anak sudah berkembang sesuai harapan yaitu 38\%, sedangkan 8 orang anak belum berkembang dengan baik $61 \%$. Berdasarkan wawancara yang dilakukan bahwa metode pembelajaran yang digunakan tidak bervariatif, pembelajaran hanya berpusat pada guru (Nuraeni, 2014). Sehingga anak tidak dapat mengekspresikan diri pada saat pembelajaran.

Sependapat dengan (Hayati, 2019) bahwa rendahnya kreativitas anak usia dini karena media dan metode pembelajaran tidak bervariasi, sehingga membuat anak tidak termotivasi untuk mengembangkan ide-ide/gagasannya. Menurut bebebapa teori bahwa pembelajaran yang hanya berpusat pada guru akan memiliki dampak pada anak salah satunya anak tidak dapat mengembangkan kreativitas dan daya kritis anak (I. Dewi \& Suryana, 2020).

Perkembangan kreativitas anak dapat dikembangkan melalui pembelajaran gerak dan lagu. Sependapat dengan penelitian Mulyani (2019) bahwa bermain gerak dan lagu pada anak usia dini memberikan dampak yang positif pada serta membatu merangsang perkembangan kreativitas kecerdasan musical melalui menari dan senam. Pembelajaran gerak dan music mampu mengembangkan perkembangan anak, seperti: perkembangan 
kepribadian anak, imajinasi, social, emosi, motoric, kognitif, serta krativitas anak (Kralova \& KolodziejskiZ, 2016).

Keterbaruan dari penelitian ini dengan penelitian sebelumnya adalah penelitian dilakukan di TK Islam Tasya Cibinong, adapun pembelajaran gerak dan lagu yang digunakan adalah tema tanaman. Menggunakan metode penelitian tindakan model Kemmis dan Mc. Taggart. Adapun tujuan dari penelitian ini adalah untuk mengetahui proses implementasi pembelajaran gerak dan lagu untuk meningkatkan kreativitas anak usia 5-6 tahun.

\section{METODOLOGI}

Penelitian ini dilakukan di TK Islam Tasya yang berjumlah 12 orang anak usia 5-6 tahu di TK Islam Tasya di Jalan Raya Pemda Kampung Kaum Pandak Cibinong. Penelitian dilaksanakan pada bulan November-Januari 2020. Metode penelitian yang digunakan adalah penelitian tindakan menggunakan model Kemmis dan Mc Taggart. Teknik pengumpulan data adalah observasi, wawancara, angket. Teknik analisis data yang digunakan data kuantitatif dan data kualitatif.

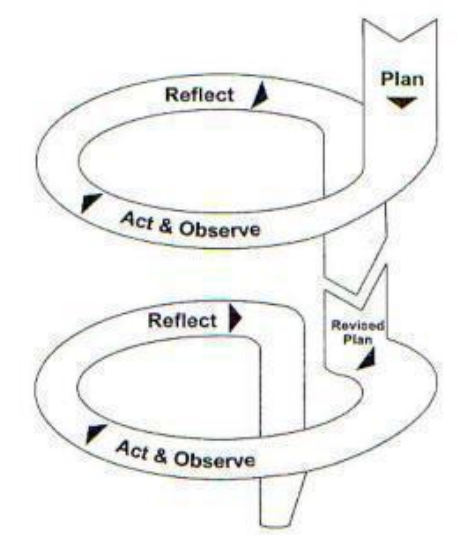

Gambar 1. Rancangan Model Penelitian Tindakan

Model Kemmis dan Mc Taggart (Yaumi \& Damopoli, 2012)

Melihat peningkatan kreativitas anak usia dini, peneliti melakukan observasi dengan menggunakan instrumen berbentuk lembar penilaian. Berikut ini tabel kisi-kisi instrumen kreativitas anak usia 5-6 tahun melalui gerak dan lagu.

Tabel 1. Kisi-kisi Instrument Penelitian Kreativitas Anak Usia 5-6 Tahun Melalui Gerak dan Lagu

\begin{tabular}{|c|l|l|c|}
\hline Variabel & Aspek & \multicolumn{1}{|c|}{ Indikator } & \multicolumn{1}{|c|}{ Nomor } \\
\cline { 3 - 4 } & & & Butir Soal \\
\hline Kreativitas & Kelancaran & 2.1 Mampu mengekpresikan diri & 2 \\
\cline { 3 - 4 } & (Fluency) & $\begin{array}{l}\text { 2.2 Memiliki gagasan spontan } \\
\text { 2.3 Memiliki Kemauan yang kuat }\end{array}$ & 2 \\
\cline { 2 - 4 } & Kelenturan & 2.1 Cenderung mengadakan percobaan & 2 \\
\cline { 3 - 4 } & (Flexibility) & sendiri & \\
& 2.2 Kemampuan menyesuaikan diri & \\
\cline { 2 - 4 } & Keaslian & 3.1 Mampu mengembangkan imajinasi & 2 \\
\cline { 3 - 4 } & (Orisinality) & 3.2. Tidak terpengaruh dari luar & 2 \\
\cline { 3 - 4 } & 3.3. mampu mempertahankan ide & 2 \\
\cline { 2 - 4 } & Penguraian & 4.1. Penggunaan banyak unsur & 2 \\
\cline { 3 - 4 } & (Elaboraty) & 4.2.Mampu menunjukan ide & 2 \\
\hline
\end{tabular}


Instrument yang dikembangkan peneliti berbentuk checklist, dengan pola jawaban berskala likert. Berikut ini tabel skala kemunculan kreativitas anak dan ketentuan intensitasnya.

Tabel 2. Skala Kemunculan Kreativitas

\begin{tabular}{|l|c|}
\hline \multicolumn{1}{|c|}{ Jawaban } & Skor \\
\hline Berkembang sangat baik & 4 \\
\hline Berkembang sesuai harapan & 3 \\
\hline Mulai berkembang & 2 \\
\hline Belum berkembang & 1 \\
\hline
\end{tabular}

Tabel 3. Ketentuan Intensitas Kemunculan

\begin{tabular}{ll} 
Jawaban & Skor \\
\hline Berkembang sangat baik & Sikap perilaku yang di amati muncul lebih dari 4 kali \\
\hline Berkembang sesuai harapan Sikap perilaku yang di amati muncul 3-4 kali \\
\hline Mulai berkembang & $\begin{array}{l}\text { Sikap perilaku yang di amati muncul lebih dari 1-2 } \\
\text { kali }\end{array}$ \\
\hline Belum Berkembang & Sikap perilaku yang di amati tidak muncul \\
\hline
\end{tabular}

\section{HASIL DAN PEMBAHASAN}

Langkah-langkah pembelajaran melalui gerak dan lagu adalah peneliti memperkenalkan nama dan menyampaikan pembelajaran dan aturan saat belajar dan bermain, dan peneliti meminta anak memperkenalkan namanya. Namun masih ada anak yang berebut menyebutkan namanya bahkan menyebutkan nama temannya. Beberapa anak masih terlihat malu -malu dan belum percaya diri .

Kegiatan selanjutnya peneliti menjelaskan pembelajaran hari ini dengan memperlihatkan gambar sesuai tema yaitu pohon, setelah diperlihatkan gambar peneliti bercerita tentang pohon dan melakukan tanya jawab dengan anak-anak, beberapa anak sudah berani menjawab pertanyaan dan peneliti mananyakan siapa yang mau belajar menyanyikan lagu pohon, anak-anak serentak menjawab mau, walau beberapa anak masih bersuara kecil. Peneliti mengajarkan anak-anak menyanyikan lagu Pohon dengan bertepuk tangan lalu memotivasi anak untuk melakukan berbagai Gerakan seperti pohon, terlihat beberapa anak mulai berdiri dan Sebagian hanya melihat temannya saja dan menunggu intruksi dari peneliti. Adapun hasil penelitian yang didapatkan yaitu:

\section{Deskripsi Data Siklus I}

Perencanaan. Pada siklus I tindakan yang di berikan, dilakukan secara bertahap selama 6 kali ertemuan sejak tanggal 9 Desember sampai 18 Desember 2019. Setiap kali pertemuan berlangsung $1 \times 60$ menit. Tindakan yag diberikan menggunakan model Kemmis dan Taggart. Sebelum melakukan tindakan,peneliti bersama kolaborator mendiskusikan rencana tindakan yang akan dilakukan selanjutnya, selain itu ada persiapan lainnya yaitu instruen pemantau tindakan dengan alat dokumentasi, kamera telepon genggam, kamera DSLR. Berikut merupakan deskripsi penerapan kretivitas melalui kegiatan gerak dan lagu. Setiap pertemuantelah dilakukan perencanaan hingga refleksi. Dalam kegiatan perencanaan tindkan siklus I peneliti bersama kolaborator melakukan berbagai hal untuk membantu dalam mengumpulkan data, diantaranya sebagai berikut: (a) Merancang gerak dan lagu yang sesuai tema yang akan ditampilkan saat proses pembelajaran gerak dan lagu. (b) Merancang jadwal pembelajaran yang akan diberikan kepada anak selama 6 kali tindakan di siklus I. Pembelajaran gerak dan lagu dilaksanakan selama 6 kali pertemuan. (c) Menyusun rencana program pembelajaran harian $(\mathrm{RPPH})$ melalui pemelajaran gerak dan lagu bersama 
kolaborator. (d) Menyiapkan alat pengumpul data berupa catatan lapangan, lembar pedoman observasi dan alat dokumentasi (camera). (e) Setelah membuat perencanaan tindakan peneliti bersama kolaborator melkasnakan tindakan I.

Tabel 4. Data Kreativitas Anak Pra Siklus dan Siklus I

\begin{tabular}{|c|c|c|c|c|c|c|}
\hline \multirow{2}{*}{ No } & \multirow{2}{*}{$\begin{array}{c}\text { Nama } \\
\text { Responden }\end{array}$} & \multicolumn{2}{|c|}{ Prasiklus } & \multicolumn{2}{c|}{ Siklus I } & Kategori \\
\cline { 3 - 6 } & Skor & Persentase & Skor & Persentase & \\
\hline $\mathbf{1}$ & CIT & 8.5 & 46.87 & 59.25 & 55.03 & BSH \\
\hline $\mathbf{2}$ & MIK & 4.75 & 29.46 & 45.5 & 42.44 & MB \\
\hline $\mathbf{3}$ & ADB & 6.25 & 39.43 & 39.25 & 36.45 & MB \\
\hline $\mathbf{4}$ & MN & 6 & 33.33 & 37 & 34.37 & MB \\
\hline $\mathbf{5}$ & ADF & 4.75 & 26.56 & 37 & 34.28 & BB \\
\hline $\mathbf{6}$ & IN & 5.75 & 32.29 & 53.5 & 49.82 & MB \\
\hline $\mathbf{7}$ & BAL & 5.25 & 29.68 & 46.25 & 42.96 & MB \\
\hline $\mathbf{8}$ & ZAQ & 7.75 & 42.18 & 60.25 & 56.25 & BSH \\
\hline $\mathbf{9}$ & FA & 7.25 & 40.1 & 60.25 & 56.16 & BSH \\
\hline $\mathbf{1 0}$ & HAN & 7 & 38.54 & 61.25 & 57.11 & BSH \\
\hline $\mathbf{1 1}$ & RAY & 6.75 & 38.02 & 44.75 & 42.1 & MB \\
\hline $\mathbf{1 2}$ & IKB & 6.5 & 35.93 & 46 & 43.22 & MB \\
\hline & Rata-Rata & $\mathbf{6 . 3 7 5}$ & $\mathbf{3 6 . 0 3 2 5}$ & $\mathbf{4 9 . 1 8 7 5}$ & $\mathbf{4 5 . 8 4}$ & \\
\hline
\end{tabular}

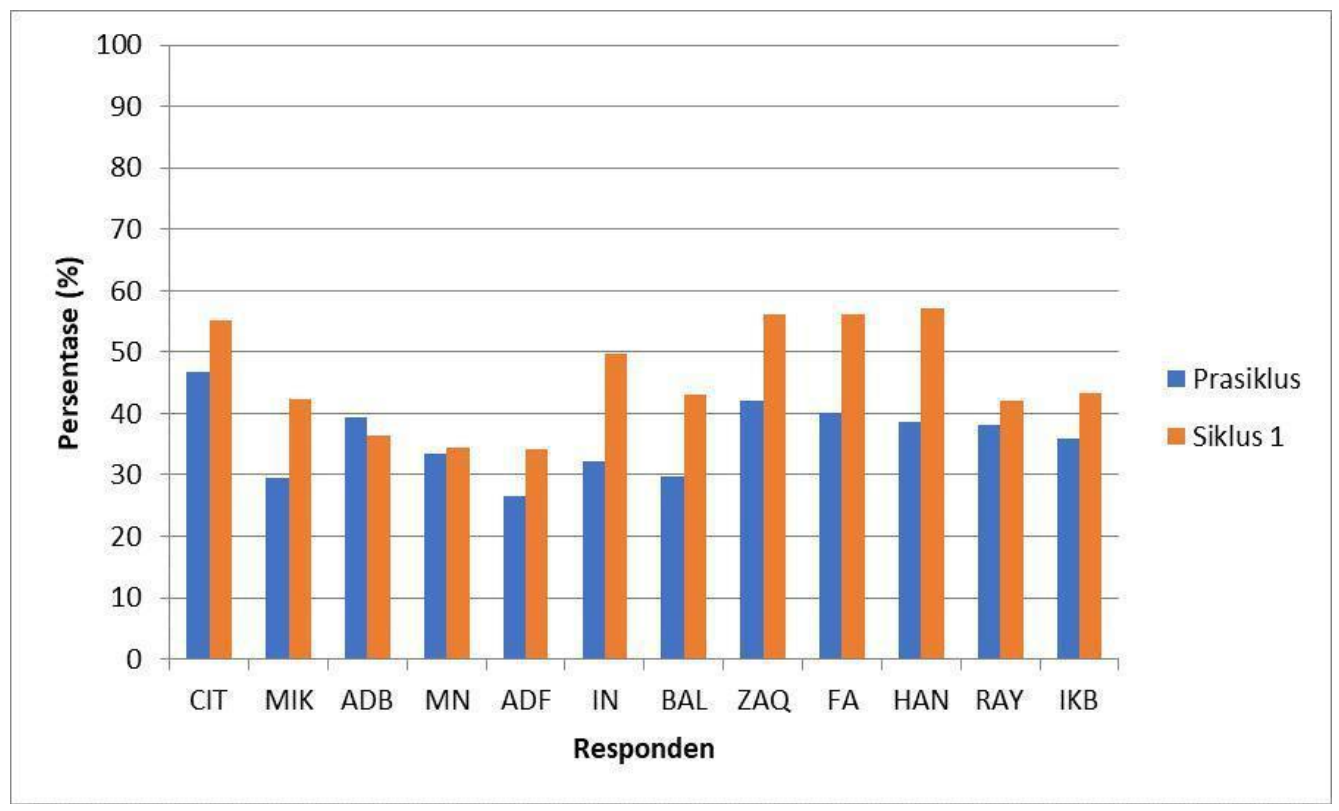

Gambar 2. Grafik Kreativitas Anak Pra Siklus dan Siklus I

Berdasarkan data tabel di atas pencapaian kreativitas anak dapat diketahui bahwa setiap anak mengalami peningkatan, namun belum mencapai target yang di sepakati oleh kolaborator dan peneliti, pencapaian target yang dimaksud adalah $71 \%$. Pada tindakan siklus I, jika dilihat dari grafik di atas nilai teringgi di peroleh oleh HAN, FA, ZAQ kemudian nilai terendah oleh $\mathrm{MN}$ dan $\mathrm{ADF}$ dengan rata-rata presentase yang di peroleh pada siklus I mencapai $45,84 \%$, sedangkan prasiklus 36,032. Hal ini mengalami peningkatan dengan rata-rata katagori Mulai Berkembang (MB). Kreativitas anak telah mengalami perkembangan walaupun belum mencapai target yang di inginkan. Hasil ini memberikan kesimpulan bahwa penelitian perlu dilanjutkan dengan pemberian tindakan pada siklus II.

Refleksi (Reflecting). Berdasarkan hasil siklus I yang dilaksanakan enam 6 kali pertemuan dapat di katahui, bahwa tingkat capaian krativitas anak dengan rata-rata dengan katagori Berkembang sesuai harapan (BSH) Akan tetapi belum memenuhi tingkat capaian 
penilai yang telah disepakai. Pada siklus I ditemukan beberpa hal diantaranya: (a) Pada saat diberikan tindakan pertemuan pertama dan kedua anak-anak terlihat belum fokus, hanya beberapa orang saja yang aktif. (b) Pada pertemuan pertama siklus I, peneliti melakukan percakapan tentang tema, anak cenderung masih pasif dan malu. (c) Pada saat pembelajaran gerak dan lagu siklus I, anak-anak masih kurang bersemangat menghapal lagu baru. (d) Pada saat pembelajaran, beberapa anak terlihat hanya aktif jika di ajak kawannya atau peneliti.

Adanya permasalahan yang di temukan dari hasil tindakan siklus I selama 6 kali pertemuan, peneliti dan kolaborator melanjutkan ke siklus II dengan melakukan beberapa perubahan, seperti: selalu memberikan motivasi kepada anak, memberikan pemahaman agar berani mencoba, berani bertanya serta bercerita saat gerak dan lagu. Pada siklus II ini peneliti dan kolaborator akan menggunakan lagu dan musik, mengganti tema agar aspek kelancaran, keluwesan memperinci dan keaslian dapat meningkat. Peneliti dan kolaborator akan menentukan tema dan lagu yang sesuai untuk gerak dan lagu.

\section{Deskripsi Data Siklus II}

Perencanaan. Pada siklus II tindakan yang diberikan, dilakukan secara bertahap selama 6 kali pertemuan sejak tanggal 13 januari sampai dengan 22 januari 2020, setiap kali pertemuan selama 60 menit. Sebelum melakukan tindakan peneliti bersama kolabirator mendiskusikan program pembelajaran yang akan di lakukan pada siklus II.Selanjutnya peneliti menyiapkan instrumen dan alat dokumentasi berupa camera telepon genggam dan camera DSLR

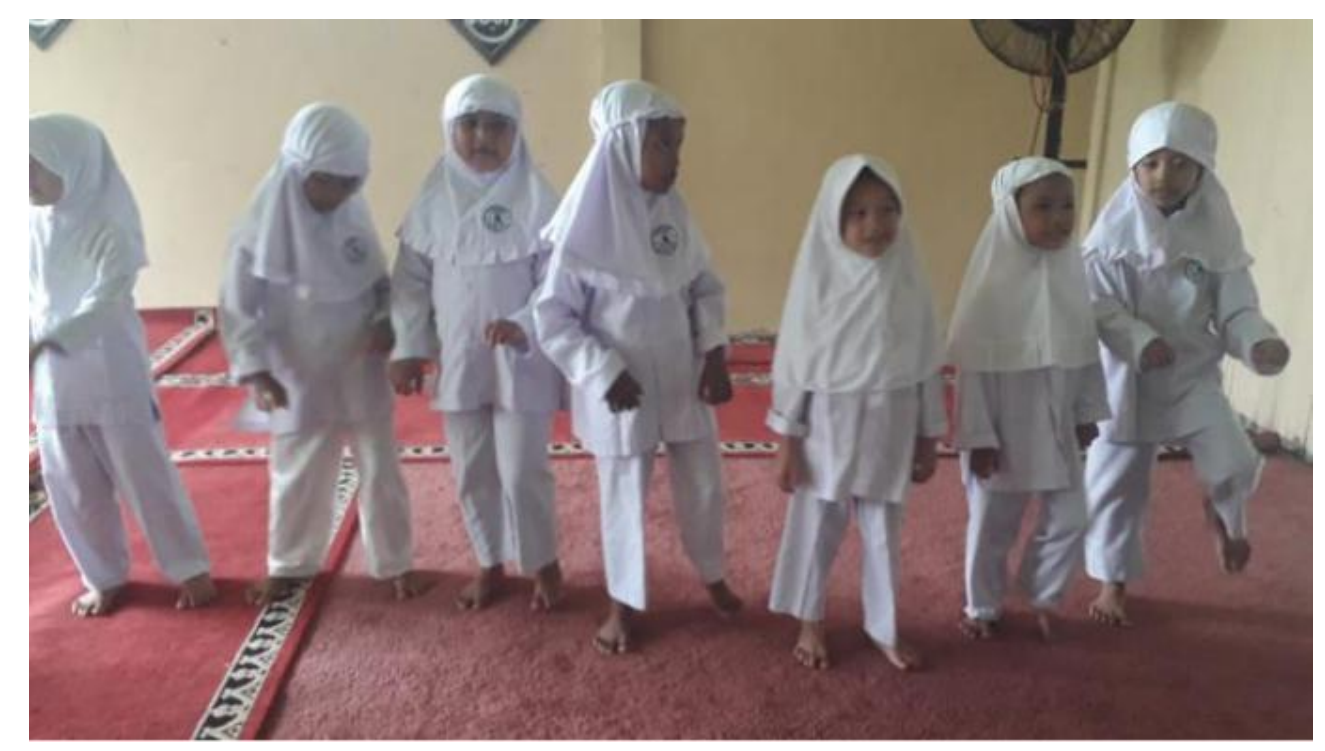

Gambar 3. Mengulang Gerakan dan Lagu

Pada gambar di atas anak-anak mengulang kembali gerakan dan lagu pada pertemuan sebelumnya. Peneliti mengajak anak melakukan gerakan dan lagu dengan mendengarkan cerita dengan tema kupu-kupu cantik. Anak-anak bergerak dan bernyayi mengikuti alur cerita yang dibacakan.

Pada pertemuan di siklus II, kreativitas semua anak terlihat tanpa perlu banyak arahan dari guru. Anak dapat belajar dalam kelompok, dapat mengekspresikan diri, dapat percaya diri dalam membuat gerak dan lagu. Anak terlihat bersemangat selama mengikuti pembelajaran gerak dan lagu, saling membantu dan menghargai karya sendiri ataupun karya temannya. Berdasarkan hal tersebut anak telah mampu mencapai indicator kreativitas yang diharapkan. Berikut adalah hasil pencapaian penilaian kreativitas anak pada siklus II. 
Tabel 5. Data Kreativitas Anak Siklus I dan Siklus II

\begin{tabular}{|c|l|l|l|l|l|l|}
\hline & \multicolumn{1}{|c|}{ Nama } & \multicolumn{2}{|c|}{ Siklus 1 } & \multicolumn{2}{c|}{ Siklus 2 } & \multirow{2}{*}{ Kategori } \\
\cline { 2 - 6 } & Responden & \multicolumn{1}{|c|}{ Skor } & \multicolumn{1}{|c|}{ Persentase } & \multicolumn{1}{|c}{ Skor } & Persentase & \\
\hline $\mathbf{1}$ & CIT & 59.25 & 55.03 & 85.5 & 78.73 & BSB \\
\hline $\mathbf{2}$ & MIK & 45.5 & 42.44 & 72 & 67.27 & BSH \\
\hline $\mathbf{3}$ & ADB & 39.25 & 36.45 & 65 & 60.24 & BSH \\
\hline $\mathbf{4}$ & MN & 37 & 34.37 & 64.5 & 60.15 & BSH \\
\hline $\mathbf{5}$ & ADF & 37 & 34.28 & 67.75 & 62.76 & BSH \\
\hline $\mathbf{6}$ & IN & 53.5 & 49.82 & 79 & 73.17 & BSH \\
\hline $\mathbf{7}$ & BAL & 46.25 & 42.96 & 68 & 63.1 & BSH \\
\hline $\mathbf{8}$ & ZAQ & 60.25 & 56.25 & 91.75 & 84.72 & BSB \\
\hline $\mathbf{9}$ & FA & 60.25 & 56.16 & 95.75 & 87.23 & BSB \\
\hline $\mathbf{1 0}$ & HAN & 61.25 & 57.11 & 88.5 & 81.94 & BSB \\
\hline $\mathbf{1 1}$ & RAY & 44.75 & 42.1 & 79.5 & 72.48 & BSH \\
\hline $\mathbf{1 2}$ & IKB & 46 & 43.22 & 72.75 & 68.05 & BSH \\
\hline \multicolumn{2}{|l}{ Rata-rata } & 49.18 & 45.84 & 77.5 & 71.65 & \\
\hline
\end{tabular}

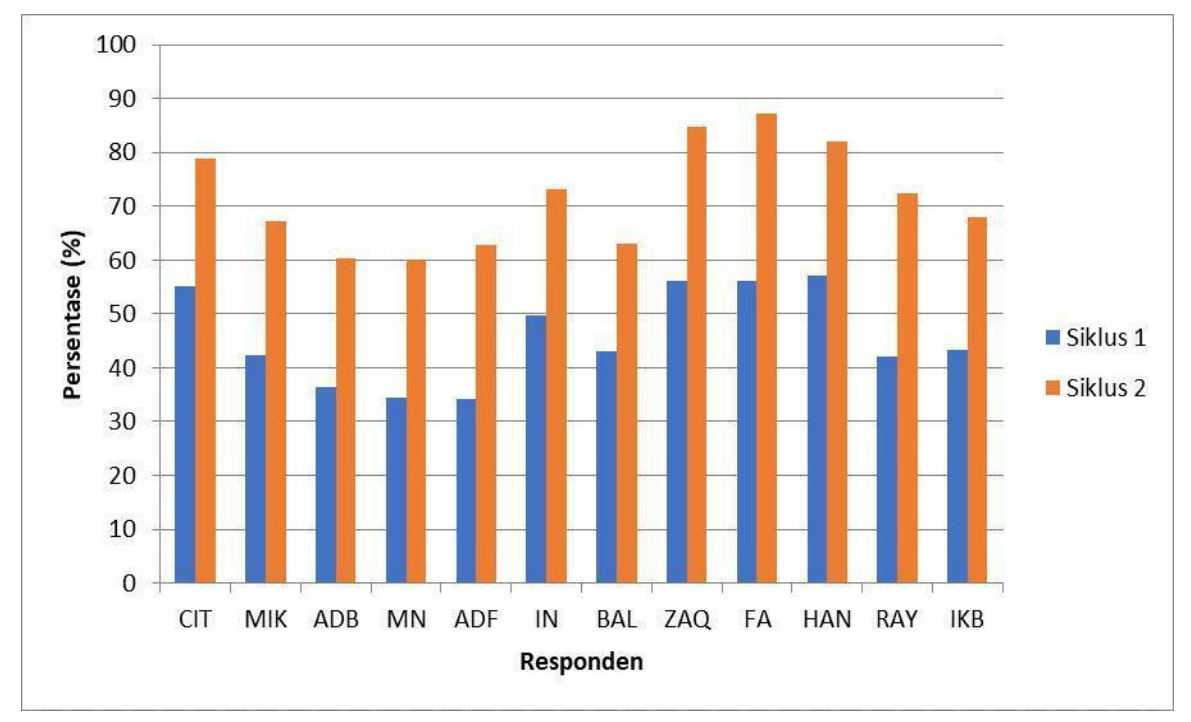

\section{Gambar 4. Grafik Kreativitas Anak Siklus I dan Siklus II}

Berdasarkan data table dan grafik di atas, menunjukan peningkatan rata-rata skor kreativitas anak melalui pemebelajaran gerak dan lagu pada siklis I dan siklus II cukup signifikan. Dapat di deskripsikan bahwa presentase rata-rata keberhasilan adalah $\mathbf{7 1 , 5 8}$ dengan kriterian sangat baik. Hal ini berarti sudah mencapai target yang telah ditetapkan yaitu sebesar $71 \%$. Berdasarkan data tersebut, maka peneliti memutuskan untuk tidak melanjutkan ke siklus berikutnya. Selain itu, peneliti dan kolaborator telah memantau presentase kenaikan yang terjadi pada setiap siklusnya sesuai target pada siklus I, apabila presentase kreativitas terus meningkat maka presentase kenaikan dinyatakan signifikan. Pada siklus II nilai teringgi mencapai 88 dan 91 yang diraih oleh ZAQ, FA, CIT, dengan katagori Berkembang sangat baik (BSB) data terendah sebesar 64,5 dengan katagori berkembang sesuai harapan (BSH) diraih oleh $\mathrm{MN}$.

Refleksi (Reflecting). Berdasarkan data dari observasi, aktifitas guru dan anak telah berjalan baik sesuai dnegan perencanaan, disertai dnegan memberikan pemahaman kepada anak dalam prosem implikasi aspek perencanaa, keluwesan keaslian dan memperinci. Pada pertemuan pertama hingga pertemuan ke empat, pembelajaran gerak dan lagu telah berjalan dengan lancra sesuai dengan yang diharapkan. Setiap anak mengalami peningkatan dari siklus I ke siklus II. Rata-rata presentase kreativitas anak meningkat setelah diberikan 
Tindakan gerak dan lagu pada anak kelompok B TK Islam Tasya dapat dihentikan hanya sampai siklus II. Pemeriksaan keabsahan data pada penelitian ini menggunakan bebrapa tehnik validasi data. Adapun tehnik validasi data yang digunakan adalah sebagai berikut: (1) Perpanjangan Waktu. Perpanjangan Waktu keikutsertaan dilakukan peneliti melalui Tindakan sebelum siklus berikutnya dirancang. Melalui perpanjangan waktu itu memungkinkan peneliti untuk menemukan,mengungkapkan dan mendalami temuantemuan terkait pelaksanaan pembelajaran gerak dan lagu untuk meningkatkan kreativitas anak. (2) Ketekunan pengamatan. Ketekunan pengamatan dilakukan pada saat mengadkan pengamtan lapangan sehingga dpaat menemukan hal-hal yang secara terperinci mengenai proses pembeljaran gerak dan lagu dnegan melakukan pengamatan, penelitian akan mengetahui factor-faktor yang mempengaruhi kegiatan kegiatan tersebut dilakukan dnegan mencocokan data yang ditemukan saat dilapangan melalui foto dan video serta menuangkan dalam bentuk catatan lapangan.

Berdasarkan hasil penelitian yang dilakukan ditemukan bahwa pembelajaran melalui gerak dan lagu tersebut dapat meningkatkan kreativitas anak. Hasil penelitian ini di dukung oleh hasil penelitian yang dilakukan oleh (Chronopoulou \& Riga, 2012) bahwa pembelajaran musik dan gerak di Taman Kanak-kanak menunjukkan peningkatan kreativitas anak, di mana anak dapat mengekspresikan emosinya serta pembelajaran menjadi aktif. Menurut Kilpatrick (2020) pembelajaran lagu dan gerak tidak dapat dipisahkan, karena gerak merupakan elemen yang terkait dengan music. Elemen-elemen tersebut dapat mengembangkan kognitif yang berkaitan dengan kreativitas seseorang.

Sejalan dengan E. K. Dewi et al., (2015) bahwa music dan gerak dapat menumbuhkan suasana yang menyenangkan, mengasyikkan, dan memberikan hal yang positif bagi anak ketika mengembangkan perkembangan anak. Dengan adanya gerak dan music berpotensi meningkatkan kerja otak, minat, aktivitas, social. Selain itu, music dan lagu mampu meningkatkan memori jangka pendek dan meningkatkan proses informasi dan ide kreatif anak.

Mulyani (2019) mengungkapkan bahwa gerak dan lagu ialah pembelajaran yang sangat tepat untuk mengembangkan kreativitas anak usia dini, karena gerak dan lagu berkaitan sangat erat. Pembelajaran gerak dan lagu adalah kegiatan yang dilakukan belajar sambil bermain, sehingga membuat kegiatan menjadi menyenangkan dan menarik untuk anak. Gerak dan lagu tidak hanya dapat meningkatkan kreativitas anak, melainkan membantu meningkatkan perkembangan lainnya, seperti: bahasa, kognitif, social emosional, dan fisik motoric anak. Hal ini sependapat dengan Kralova \& KolodziejskiZ (2016) kegiatan gerak dan lagu tidak hanya dapat mengembangkan kreativitas anak, melainkan mampu mengembangkan aspek perkembangan lainnya, seperti: motoric, emosi, kepribadian dan lain-lain.

Dalam meningkatkan kreativitas anak, hendaknya guru mampu membuat pembelajaran yang menyenangkan dan menarik untuk anak. Ketika pembelajaran tersebut menarik, maka anak akan mudah menerima dan memahami suatu materi yang akan diperlajari. Sebaiknya hindari pembelajaran yang hanya berpusat pada guru, tetapi libatkanlah anak dalam pembelajaran agar anak menjadi aktif dan kreatif.

\section{SIMPULAN}

Pembelajaran gerak dan lagu sangatlah penting diimplementasikan pada anak usia dini. Gerak dan lagu memiliki dampak yang baik untuk anak yang dapat mengembangkan kognitif, kognitif berkaitan dengan kreativitas anak. Dengan berkembangnya kreativitas anak, maka memberikan ide atau gagasan yang ada. hasil penelitian menunjukkan bahwa pembelajaran gerak dan lagu dapat meningkatkan kreativitas pada anak usia dini. Hal ini disebabkan karena anak dapat mengekspresikan emosinya secara aktif, sehingga anak mampu menuangkan ide-ide kreatif dalam pembelajaran. 


\section{UCAPAN TERIMA KASIH}

Peneliti mengucapkan terima kasih banyak untuk pihak-pihak terkait dalam pembuatan artikel ini, khususnya TK Islam Tasya Cibinong yang telah memberikan kesempatan untuk melakukan penelitian.

\section{DAFTAR PUSTAKA}

Ayuni, D., \& Setiawati, F. A. (2019). "Kebun Buah" Learning Media for Early Childhood Counting Ability Despa. Jurnal Obsesi: Jurnal Pendidikan Anak Usia Dini, 3(1), 1-9. https://doi.org/10.31004/obsesi.v3i1.128

Chronopoulou, E., \& Riga, V. (2012). The Contribution of Music and Movement Activities to Creative Thinking in Pre-School Children. Creative Education, 3(2), 196-204. https:// doi.org/10.4236/ce.2012.32031

Dere, Z. (2019). Investigating the Creativity of Children in Early Childhood Education Institutions. Universal Journal of Educational Research, 7(3), 652-658. https://doi.org/10.13189/ujer.2019.070302

Dewi, E. K., Rusmawati, D., \& Ratnaningsih, I. Z. (2015). The Effect of Music and Motoric Movement Intervention to Increase Attention among Elementary School Studentsin Semarang Central Java. Procedia Environmental Sciences, 23(Ictcred 2014), 179-185. https://doi.org/10.1016/j.proenv.2015.01.028

Dewi, I., \& Suryana, D. (2020). Analisis Evaluasi Kinerja Pendidik Pendidikan Anak Usia Dini di PAUD Al Azhar Bukittinggi. Jurnal Obsesi: Jurnal Pendidikan Anak Usia Dini, 4(2), 1051. https://doi.org/10.31004/obsesi.v4i2.465

Elya, M. H., Nadiroh, N., \& Nurani, Y. (2019). Pengaruh Metode Bercerita dan Gaya Belajar terhadap Kemampuan Berbicara Anak Usia Dini. Jurnal Obsesi: Jurnal Pendidikan Anak Usia Dini, 4(1), 312. https:/ / doi.org/10.31004/obsesi.v4i1.326

Glăveanu, V. P. (2011). Children and creativity: A most (un)likely pair? Thinking Skills and Creativity, 6(2), 122-131. https:// doi.org/10.1016/j.tsc.2011.03.002

Hayati, Z. (2019). Penggunaan Alat Permainan Edukatif (APE) dari Botol Plastik dan Koran Bekas untuk Mengingkatkan Kreativitas AUD. AWLADY : Jurnal Pendidikan Anak, 5(1), 56. https://doi.org/10.24235/awlady.v5i1.3457

Kilpatrick, C. E. (2020). Movement, Gesture, and Singing: A Review of Literature. Update: Applications of Research in Music Education, 38(3), 29-37. https:// doi.org/10.1177/8755123320908612

Kralova, E., \& KolodziejskiZ, M. (2016). Music and Movement Activities for Preschool Children as An Incentive to Foster Relationships and the Expression of Movement. Eetp, 11(3 (41)), 185-205. https://doi.org/10.14632/eetp.2016.11.41.185

Mulyani, N. (2019). Pengembangan Kreativitas Anak Usia Dini Melalui Bermain Gerak Dan Lagu Di TK Negeri Pembina Kabupaten Purbalingga. Aș-Șibyān: Jurnal Pendidikan Anak Usia Dini, 4(1), 13-24. https://doi.org/10.32678/aṣ-șibyān.v4i1.1961

Nuraeni, N. (2014). Strategi Pembelajaran Untuk Anak Usia Dini. Prisma Sains : Jurnal Pengkajian Ilmu Dan Pembelajaran Matematika Dan IPA IKIP Mataram, 2(2), 143. https:// doi.org/10.33394/j-ps.v2i2.1069

Samsudin, M. A., Bakar, K. A., \& Noor, N. M. (2019). The Benefits of Music and Movement in Early Mathematics. Creative Education, 10(12), 3071-3081. https://doi.org/10.4236/ce.2019.1012231

Sujiono, Y. N., \& Sujiono. (2010). Bermain Kreatif Berbasis Kecerdasan Jamak. PT Indeks.

Suryani, N. A., \& Haryono, M. (2018). Improvement of the Logical Intelligence Through Media Kolak (Collage Numbers) Based on Local Wisdom on Early Childhood. Jurnal Obsesi: Jurnal Pendidikan Anak Usia Dini, 2(2), 253. https:/ / doi.org/10.31004/obsesi.v2i2.90

Susanto, A. (2011). Perkembangan Anak Usia Dini Penghantar dalam Berbagai Aspeknya. Kencana.

Tsai, K. C. (2012). Play, Imagination, and Creativity: A Brief Literature Review. Journal of Education and Learning, 1(2), 15-20. https://doi.org/10.5539/jel.v1n2p15

Yaumi, \& Damopoli. (2012). Action Research, Teori, Model, dan Applikasi. Kencana. 